centring on radiation effects, will be held in Paris in October 1984. The project has an office at the Department of Chemistry, University of Essex, Wivenhoe Park, Colchester, Essex CO4 3SQ, England, UK, where a writing session is planned for early in the summer of 1985.

The Steering Committee is aiming for a final report to be issued during the summer of 1985 , and does not expect to release any of its findings until then. The matter is of such importance, and speculation about the range and magnitude of effects is unfolding so rapidly, that prudence suggests no publication until the full appraisal has been completed.

GILBERT F. WHITE
Institute of Behavioral Science
Campus Box 482
University of Colorado
Boulder
Colorado 80309, USA.

\title{
'Bombing' Forest Fires: A Proposed Technology
}

A West German engineer has developed the concept of a 'bomb' approach to controlling fires that spread through large natural areas. Dipl.-Ing. Malay Modak, of West Berlin, suggests that plexiglass spheres filled with compressed carbon dioxide and nitrogen, when dropped into burning areas, can serve as effective fire-extinguishers by releasing fire-smothering gases.

Modak's proposal is of scientific interest from the viewpoint of increasing efficiency of aerial fire-extinguishing efforts. Spreading water from airplanes, the traditional approach, requires heavy loading of firefighting aircraft from sources which must be relatively close to fires. Dropped water often misses its target or is rapidly dissipated by the heat of the flames that it aims to douse; and the closer a fire-fighting aircraft comes to a fire, the more dangerous the mission becomes. The idea of solid containers of extinguishant which could be dropped directly into a fire, with high probability that it would not be released until reaching the hottest part of the flames, is thus of appeal. In Modak's approach, hundreds of plexiglass 'bombs', which would resemble small earthsatellites (complete with protruding rods to prevent the balls from rolling) could simply be loaded into the holds of fire-fighting aircraft and released into pinpointed areas. The 'bombs' would not degrade until reaching the heart of the fire, at which time they would explode, causing layers of carbon dioxide to spread over the flames, as well as nitrogen gas to help promote an inert atmosphere for retarding or slowing combustion.

The major drawbacks of the bomb approach are materials and money. What Modak is proposing, essentially, is a system of throwaway fire extinguishers, which are strong enough to contain compressed gases under non-fire conditions. Finding the right materials at the right price would pose a challenge; insufficient materials and poor bomb-design would mean premature explosion of the devices, with costly and potentially disastrous results. At the same time, high-strength bombs would most probably be prohibitively expensive.

It would appear that some laboratory-scale work on fire-extinguishing bombs of the proposed nature might be worth while. They could conceivably prove to be effective components of thermally-activated fire-extinguishing systems and even have other far-reaching applications. Modak proposes, for example, that his bombs could be used for extinguishing oil-slick fires on water, for home and building fire-extinguishers, and even for acid rain control. Further information may be obtained from: Dipl.-Ing. Malay Modak, Danckelmannstrasse 35, 1000 Berlin 19, West Germany, Tel. 3224606.

\author{
Arthur H. Purcell, Director \\ Resource Policy Institute \\ 1346 Connecticut Avenue, Suite 217 \\ Washington \\ DC 20036, USA.
}

\section{Henderson Island Saved}

Some months back (Environmental Conservation, 10(2), pp. 171-3, 1983) we called attention to a serious threat to Henderson Island, the last remaining essentially pristine elevated coral atoll in the oceanic Pacific. A wealthy American stripminer had asked the British Government for permission to build a home, landing facilities, and an airstrip, on this small uninhabited island near Pitcairn, of Bounty mutiny fame. He had offered, as inducement, to build an airstrip on Pitcairn and to give the Pitcairn people $\$ 800,000$ 'to better their living conditions'. The result of this proposal, if accepted, would have been to destroy both Henderson and Pitcairn as functioning systems, and to sacrifice all future opportunity to study a practically unaltered set of island ecosystems as a baseline for observations on other, changing, islands.

When word of this proposal leaked out, hurried efforts were made to alert such organizations as the Pacific Science Association, the Royal Society of London, the Smithsonian Institution, and various other British and US conservation groups. A storm of protest resulted, directed to the British Commonwealth Office. Much debate ensued as to the relative values of maintaining intact the one remaining example of an important type of island and of major financial assistance to a small, isolated group of people of great historical and sociological interest. In this connection the question was raised as to whether such outside 'assistance' would not destroy this tiny culture, as such, by breaking down its isolation and absorbing it into the body of Western culture.

The desirability of carrying out an ecological study of Henderson Island, before the threatened change or any alteration took place, was emphasized, and possibilities of funding such an expensive undertaking were discussed, but with little result.

We are now happy to announce that permission to settle on Henderson Island has been denied by the British authorities 'for administrative and environmental reasons'. The threat to the island's integrity has been, at least for now, averted.

Possibilities for at least a limited study of Henderson Island 
are now being investigated by the Smithsonian authorities, with the hope of cooperation from the Royal Society of London and international conservation agencies.

A much-to-be-hoped-for result might be to have the Pitcairn Island Group, including also Oeno and Ducie atolls, given World Heritage status, which would be helpful to the Pitcairn Islanders. Meanwhile, it is a great satisfaction and morale-lifter to be able to claim a victory in international conservation and point to an indication of public appreciation of the importance of the ecological study of islands.

\section{F. RAYMOND FOSBERG, Botanist Emeritus National Museum of Natural History \\ Smithsonian Institution \\ Washington, DC 20560 \\ USA.}

\section{Sir John Adams, 1920-84}

Probably more than any other individual, Sir John Adams was responsible for the remarkable growth and development of the European Centre for Nuclear Research (CERN), which currently occupies a site of 480 hectares (with an even larger area reserved for possible future development), has in addition various underground tunnels of which the Super Synchrotron one alone is $7 \mathrm{~km}$ long, and employs some 3,500 people with, in addition, $c a 1,500$ working visitors mostly from member countries. Of it he was Director of the Proton Synchrotron Division before being Director-General during 1960-61, thereafter returning to England to occupy senior governmental posts before resuming at CERN as Director-General of its $300 \mathrm{GeV}$ Accelerator Project and ending up as Executive Director-General of the entire organization during 1976-80.

One might think of such a leader on the physical-and especially nuclear - side as scarcely likely to understand, much less help, our primarily biological environmentalists' one. Yet fortunately for us, John Adams also had a heart for the biological world and strong views on the necessity of shielding the environment from what we are prone to think of as 'the dirtiest garbage of all'. Thus concerning atmospheric pollution, according to a correspondent, 'He would have liked to see much more intensive fundamental research on the many problems, for he realized their complexity and felt that, on the whole, they were incompletely understood'. Like us he would advise young people desiring to make a career in the environmental wilderness of our time, to 'start with a good degree in one of the pure sciences before embarking on a course of environmental study'. The accompanying photo, taken a few years ago at the inauguration of one of Sir John's major projects, was kindly furnished by his wife Renie.

Such was the wide vision, deep perception, and ability to explain physical phenomena quite charmingly to laymen, that we were delighted when, after relinquishing his main administrative responsibilities at CERN, John Adams joined our panel of Advisory Editors of Environmental Conservation, dealing

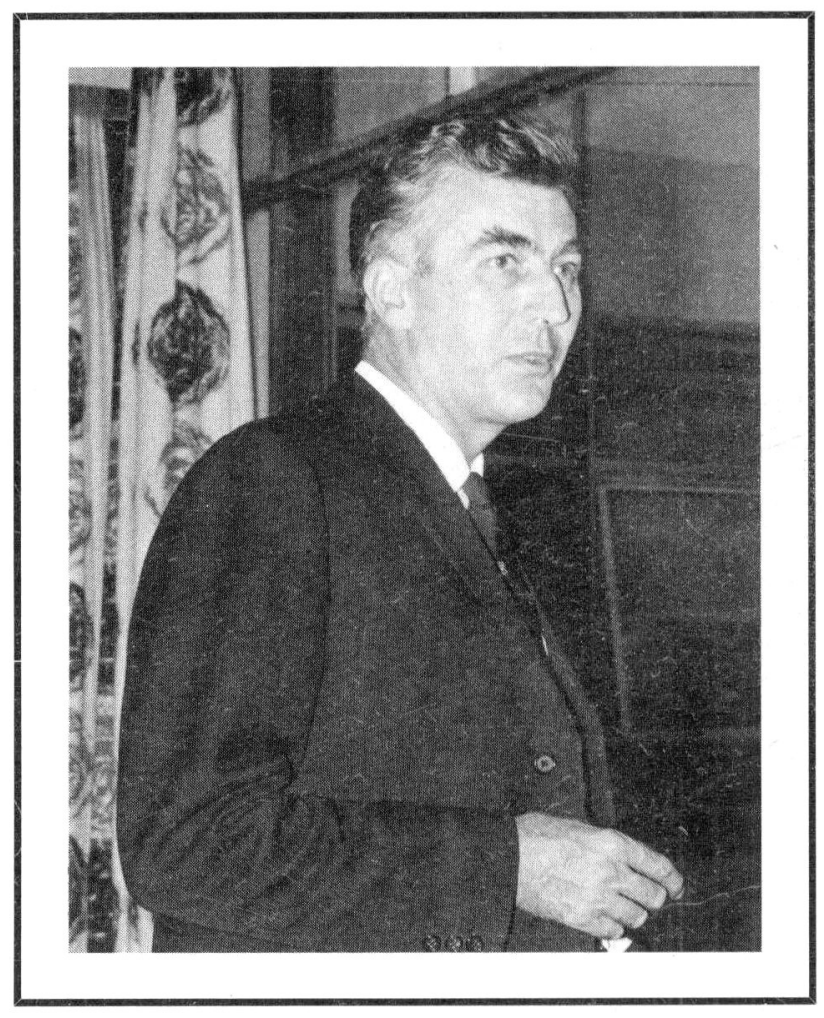

with matters pertaining to physics (apart from Energy), and so we came to benefit also from his meticulous refereeing and wise counsel. His loss to Europe and to us is great - the more so because of the shock of its prematurity-and our sympathy goes out to his family, friends, and numerous even-closer colleagues.

\section{Tolba Gold Medal}

The Energy Society of Pakistan has established an award which will be given to person(s) and/or institutions(s) making the most important contributions in the area of energy for sustainable development in developing countries. The award consists of a gold medal, named after Dr Mostafa Kamal Tolba, which will be given every second year to any individual, organization, or group of people, whose work contributes most towards the philosophy which Dr Tolba has encapsulated in his book Development Without Destruction. The recipient(s) of this international award will be chosen by an international jury of eminent persons from among the nominations received from all over the world.

The first Tolba Gold Medal will be presented in Lahore,
Pakistan, in December 1984. Nominations are invited for it of candidates who have contributed most significantly to the environmental and energy needs of developing countries in a sustainable manner. All entries received by 31 August 1984 will be considered for the first award. Nominations, with full pertinent details of candidates and their work, should be sent to the undersigned (telephone 52662 or 851583 ; Telex: 44388 GOLDN PK).

Mohammad Nazim, Secretary Energy Society of Pakistan 123-J Model Town

Lahore 14

Pakistan. 